\title{
IL-1 $\beta$ Depresses Respiration and Anoxic Survival via a Prostaglandin-Dependent Pathway in Neonatal Rats
}

\author{
ANNIKA OLSSON, GULCIN KAYHAN, HUGO LAGERCRANTZ, AND ERIC HERLENIUS \\ Karolinska Institutet, Neonatal Program, Astrid Lindgren Children's Hospital Q2:07, \\ S-171 76 Stockholm, Sweden
}

\begin{abstract}
ABST
IL- $1 \beta$ has been proposed to be an important mediator linking
infection, apnea, and sudden infant death syndrome. We hypoth-
esized that IL- $1 \beta$ acts in this capacity by depressing brainstem
respiratory neurons via a prostaglandin-dependent pathway. For
studying the effects of IL- $1 \beta$ on respiration as well as the
mechanism underlying its actions, 7 -d-old rats received an initial
injection (i.p.) of NaCl or a cyclooxygenase inhibitor (indometh-
acin, 10 mg/kg) followed by a second injection (i.p.) at 30 min of
NaCl, recombinant rat IL- $1 \beta$ ( $10 \mu \mathrm{g} / \mathrm{kg}$ ), or lipopolysaccharide
(LPS; $100 \mu \mathrm{g} / \mathrm{kg}$ ). Respiration during normoxia and in response
to anoxia ( $100 \% \mathrm{~N}_{2}$ ) was examined at 60 min after the second
injection using flow and barometric plethysmography. Animals
given IL- $1 \beta$ breathed more slowly and died more often after
anoxia. LPS also reduced the rats' ability to autoresuscitate and
survive an anoxic challenge. Indomethacin prevented the depres-
sive effects during normoxia and the adverse effects on survival.
For investigating drug-induced changes in central respiratory
activity, IL- $1 \beta$ ( 1.0 or 1.25 ng/mL) and prostaglandin $\mathrm{E}_{2}$ ( 5 or 20
\end{abstract}
Infection, hypoxia, and apnea each have been implicated in the pathogenesis of sudden infant death syndrome, and it has been postulated that the proinflammatory cytokine IL- $1 \beta$ may serve as the critical link between them $(1,2)$. IL- $1 \beta$ is released during an acute-phase immune response and subsequently induces multiple effects within the CNS, including the initiation of fever, sleep, and neuropeptide release [for review, see (3)]. Previous studies indicated that this immunomodulator may also alter respiration and autoresuscitation, yet the mechanism underlying such effects must be further elucidated (4-7). Systemic administration of IL- $1 \beta$ has been shown to induce

Received July 16, 2002; accepted January 13, 2003.

Correspondence: Eric Herlenius, M.D., Ph.D., Neonatal Research Unit, Q2:07, Department of Woman and Child Health, Astrid Lindgren Children's Hospital, Karolinska Institutet, S-171 76 Stockholm, Sweden; e-mail: eric.herlenius@dsg.ki.se

Supported by the Swedish Fulbright Commission, Swedish Research Council (5234; 22901A), National Heart and Lung Foundation, Freemason Children's House, Sven Jerring Foundation, Child Care Foundation, Swedish SIDS Parent Association, and Mayflower Foundation.

DOI: 10.1203/01.PDR.0000076665.62641.A2 $\mu \mathrm{g} / \mathrm{L}$ ) was applied to the brainstem-spinal cord preparation of 0 to 4 -d-old rats. Whereas IL- $1 \beta$ exerted no effect on respiration measured at the $\mathrm{C} 4$ ventral root during a 60 -min period, prostaglandin $\mathrm{E}_{2}$ reversibly inhibited respiratory activity. These findings suggest that IL-1 $\beta$ does not inhibit respiratory neurons directly but may depress breathing and hypoxic defense via a prostaglandin-mediated mechanism. (Pediatr Res 54: 326-331, 2003)

BBB, blood-brain barrier

\section{Abbreviations}

COX-2, cyclooxygenase-2

$\mathbf{f}_{R}$, respiratory frequency

LPS, lipopolysaccharide

NTS, nucleus of the solitary tract

$\mathbf{P G E}_{2}$, prostaglandin $\mathrm{E}_{2}$

RVLM, rostral ventrolateral medulla time- and dose-dependent expression of early immediate genes in the nucleus of the solitary tract (NTS) and rostral ventrolateral medulla (RVLM), both of which contain neurons important for respiratory control and the latter houses the central pattern generator for breathing $(8,9)$. Because of its size and lipophilic properties, IL- $1 \beta$ does not diffuse readily across the blood-brain barrier (BBB) (10). However, IL-1 $\beta$ may still communicate with the brain across the BBB via active transport passage, through circumventricular organs, vagal afferent stimulation, and via second messenger induction at the $\mathrm{BBB}$ [for review, see (11)].

We propose that IL-1 $\beta$ may affect brainstem respiratory control via a prostaglandin-dependent mechanism. This hypothesis is supported by evidence that circulating IL- $1 \beta$ induces the local release of prostaglandin $\mathrm{E}_{2}\left(\mathrm{PGE}_{2}\right)$ into the brain parenchyma and that $\mathrm{PGE}_{2}$ receptor mRNA expression and a high density of $\mathrm{PGE}_{2}$ binding occur near respiratoryrelated regions in the brainstem, such as the NTS, RVLM, nucleus ambiguus, and nucleus parabrachialis $(12,13)$. Prostaglandin has been shown to suppress fetal breathing move- 
ments as well as cause hypoventilation by decreasing respiratory frequency, induce apnea, and alter central respiratory rhythm in newborn animals (14-17). It has also been correlated with an increased number of central apneas in human neonates (18). Conversely, indomethacin, a drug that inhibits cyclooxygenase (COX) and thus prostaglandin synthesis, stimulates ventilation in both fetal and newborn animals $(19,20)$.

In the current study, we investigated whether an inflammatory response may affect respiration and the ability of rats to survive anoxic challenge through a cytokine-mediated, prostaglandin-dependent pathway. The effects of IL- $1 \beta$, lipopolysaccharide (LPS), and indomethacin on respiratory activity during normoxia and anoxia were studied in 7-d-old rats. Brainstem respiratory pattern generation after application of IL- $1 \beta$ and $\mathrm{PGE}_{2}$ was also examined in 0 - to 4 -d-old rats.

\section{METHODS}

Animals. Male and female Bkl:SD rats (B\&K Universal, Sollentuna, Sweden), postnatal ages $0-4 \mathrm{~d}$ (in vitro) and $7 \mathrm{~d}$ (in vivo), were used. The animals were born and reared by their mothers under standardized conditions with a 12-h light:12-h dark cycle. Food and water were provided ad libitum. Animals studied using flow plethysmography were handled regularly during the $3-4 \mathrm{~d}$ before experimentation. The study was performed in accordance with European Community guidelines and approved by the regional animal research ethics committee.

Drugs. Recombinant mouse IL-1 $\beta$ (Boehringer Mannheim Biochemica, Hamburg, Germany), recombinant rat IL-1 $\beta$ (Nordic BioSite AB, Täby, Sweden), LPS (from Escherichia coli serotype 0128:B12), $\mathrm{PGE}_{2}$, and indomethacin crystalline (the last three from Sigma Chemical Co.-Aldrich, Stockholm, Sweden) were used. For the in vivo study, recombinant rat IL- $1 \beta$ was mixed with $\mathrm{NaCl}$ to produce a $1 \mu \mathrm{g} / \mathrm{mL}$ of working solution. An LPS stock solution $(10 \times)$ was prepared in $\mathrm{NaCl}$, and an indomethacin stock solution $(50 \times)$ was prepared in ethanol and Trisphosphate buffer. All in vivo drugs were stored at $-20^{\circ} \mathrm{C}$ and thawed to room temperature on the day of experimentation. LPS and indomethacin were then diluted in $\mathrm{NaCl}$ to working solutions of $10 \mu \mathrm{g} / \mathrm{mL}$ and $1 \mathrm{mg} / \mathrm{mL}$, respectively. For the in vitro study, a $\mathrm{PGE}_{2}$ stock solution $(20 \times)$ was prepared in ethanol and sterile $\mathrm{H}_{2} \mathrm{O}$ and stored at $-20^{\circ} \mathrm{C}$. Concentrated solutions $(100,000 \mathrm{IU} / \mathrm{mL})$ of recombinant mouse and rat IL- $1 \beta$ were stored at $-80^{\circ} \mathrm{C}$. On the day of experimentation, the $\mathrm{PGE}_{2}$ and IL- $1 \beta$ solutions were diluted in artificial cerebrospinal fluid (aCSF) to 5 or $20 \mu \mathrm{g} / \mathrm{L}$ and 1.0 or $1.25 \mathrm{ng} / \mathrm{mL}(50-62.5 \mathrm{IU} / \mathrm{mL})$, respectively.

Flow plethysmography. A Plexiglas chamber $(110 \mathrm{~mL})$ was connected to a highly sensitive direct airflow sensor (0-200 $\mathrm{mL} / \mathrm{min}$; RSP 1040 and TRN3100 respectively, Kent Scientific Corporation, Litchfield, CT, U.S.A.). Gas flow through the chamber was maintained at approximately $110 \mathrm{~mL} / \mathrm{min}$. Gases were exchanged using a computer-controlled valve switch. Control experiments verified that $95 \%$ of gas exchange occurred within $30 \mathrm{~s}$. The flow signal was amplified by a fourchannel amplifier (P/N 770 S/N 5; SENSElab, Somedic Sales, Hörby, Sweden), converted to digital signal, and recorded at $100 \mathrm{~Hz}$ by an online computer using DasyLab software (Data- $\log \mathrm{GmbH} \&$ Co. KG, Mönchengladbach, Germany). Chamber temperature was measured continuously using a digital thermometer and recorded in parallel with the flow signal. It was maintained at $30^{\circ} \mathrm{C}$ in accordance with the documented thermoneutral zone for rats of similar age (21) by using a heating blanket attached to the chamber roof and connected to a power supply (ES 030-5; Delta Electronika, Zierikzee, The Netherlands).

Barometric plethysmography. A Plexiglas chamber (175 $\mathrm{mL}$ ) was connected along with an identical reference chamber to a highly sensitive differential pressure transducer (DP103; Validyne, Northridge, CA, U.S.A.). Pressurized gas was administered continuously into the chamber and evacuated with a vacuum pump. Inlet and outlet resistance was adjusted using needle valves to maintain atmospheric pressure in the chamber. Gas flow was maintained at $1.0 \mathrm{~L} / \mathrm{min}$, and $95 \%$ of gas exchange occurred within $30 \mathrm{~s}$ of gas administration. The pressure signal was amplified and recorded by an online computer for off-line analysis. Chamber temperature was measured using a digital thermometer and maintained at $30^{\circ} \mathrm{C}$ using a thermoradiator and heating pad.

Plethysmography protocol. Each animal $(n=112)$ received an initial injection (i.p.) of $\mathrm{NaCl}$ or indomethacin $(10 \mathrm{mg} / \mathrm{kg})$, followed by a second injection (i.p.) at $30 \mathrm{~min}$ of $\mathrm{NaCl}, \mathrm{IL}-1 \beta(10$ $\mu \mathrm{g} / \mathrm{kg}$ ), or LPS (100 $\mu \mathrm{g} / \mathrm{kg}$; the last examined using flow plethysmography only). The unrestrained animal was placed in the plethysmograph chamber $60 \mathrm{~min}$ after the second injection and exposed to room air $\left(21 \% \mathrm{O}_{2}\right.$; approximately $3 \mathrm{~min}$ and $7 \mathrm{~min}$ for barometric and flow plethysmography, respectively). The inlet gas was then switched to $100 \% \mathrm{~N}_{2}$, and respiratory activity was measured during anoxia (Fig. 1). One minute after initiation of secondary apnea, $100 \% \mathrm{O}_{2}$ was administered into the chamber (22). $\mathrm{O}_{2}$ flow continued for approximately $15 \mathrm{~min}$ or until the animal autoresuscitated, whichever occurred first. In a sample population $(n=35)$, skin temperature was measured using a thermistor probe attached to the animal's back with adhesive tape. Experiments were performed during the light cycle.

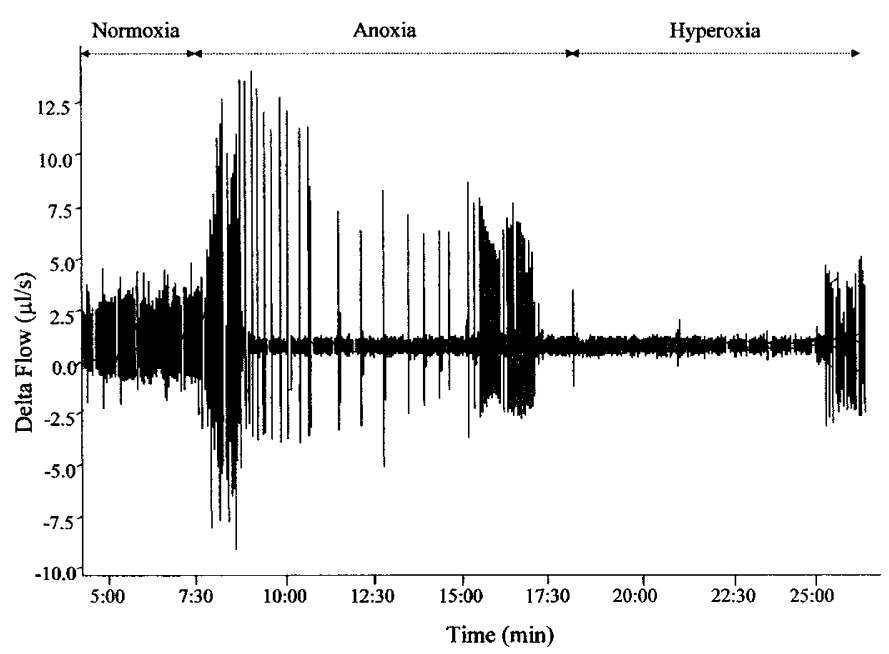

Figure 1. Basal respiration and response to anoxia. Flow plethysmograph recording depicts the respiratory activity of a control animal during normoxia (21\% $\mathrm{O}_{2}$; initial 5 min not shown), anoxia $\left(100 \% \mathrm{~N}_{2}\right)$, and hyperoxia $\left(100 \% \mathrm{O}_{2}\right)$. Note the biphasic anoxic response, including hyperpnea, primary apnea, gasping, and secondary apnea, followed by autoresuscitation during hyperoxia. 
Brainstem-spinal cord preparation. The brainstem and spinal cord of 0 - to 4-d-old rats $(n=20)$ was dissected under deep ether anesthesia and isolated as described previously $(23,24)$. The preparation was perfused continuously in a $2-\mathrm{mL}$ chamber at a rate of $3.0-3.5 \mathrm{~mL} / \mathrm{min}$ with the following aCSF: $124 \mathrm{mM}$ of $\mathrm{NaCl}, 5.0 \mathrm{mM}$ of $\mathrm{KCl}, 1.2 \mathrm{mM}$ of $\mathrm{KH}_{2} \mathrm{PO}_{4}, 2.4 \mathrm{mM}$ of $\mathrm{CaCl}_{2}, 1.3 \mathrm{mM}$ of $\mathrm{MgSO}_{4}, 26 \mathrm{mM}$ of $\mathrm{NaHCO}_{3}$, and 30 of $\mathrm{mM}$ glucose. The aCSF was equilibrated with $95 \% \mathrm{O}_{2}$ and $5 \% \mathrm{CO}_{2}$ to $\mathrm{pH} 7.4$ at $28.5^{\circ} \mathrm{C}$.

Respiratory activity was recorded using suction electrodes applied to the proximal end of the cut $\mathrm{C} 4$ ventral root containing respiratory motoneuron axons. $\mathrm{C} 4$ activity, corresponding to phrenic nerve discharge (24), was amplified and band-pass filtered ( $10 \mathrm{~Hz}$ to $5 \mathrm{kHz}$; differential AC amplifier model 1700; A-M Systems, Everett, WA, U.S.A.), rectified, and then integrated by a third-order R-C filter (time constant $100 \mathrm{~ms}$ ). C4 activity was monitored continuously using Axotape and Axoscope programs (Axon Instruments, Foster City, CA, U.S.A.). It was digitized $(1-5 \mathrm{kHz})$ and stored on a computer hard drive for off-line analysis. After perfusion with control aCSF for 30-50 min, the drug-containing aCSF solution was applied for $30 \mathrm{~min}$. IL-1 $\beta$ perfusion was continued for $60 \mathrm{~min}$ in five preparations. Drug application was followed by washout with the control aCSF.

Measurements and analysis. From the plethysmograph recordings during normoxia, at least three periods of $10-60 \mathrm{~s}$ with minimal movement artifacts were selected. Mean respiratory frequency $\left(\mathrm{f}_{\mathrm{R}}\right.$; breaths $/ \mathrm{min}$ ) was determined for each animal. Inspiratory time (s), expiratory time (s), tidal volume $(\mathrm{mL} /$ breath), and minute ventilation $(\mathrm{mL} / \mathrm{min})$ were also calculated from the flow plethysmograph data. The duration of hyperpnea, primary apnea, and gasping as well as the gasping frequency were determined manually. The gasping period of animals examined using flow plethysmography was further divided into three phases as described previously (25). The duration and gasping frequency of each phase were calculated manually. Survival was recorded for all animals, and the duration of secondary apnea and time required to autoresuscitate after $\mathrm{N}_{2}$ administration were determined in survivors. In vitro recordings were analyzed using Axoscope and JMP (SAS Institute, Cary, NC, U.S.A.). Respiratory frequency $\left(\mathrm{f}_{\mathrm{R}} ;\right.$ burst $\left./ \mathrm{min}\right)$ was calculated from the mean $\mathrm{C} 4$ burst interval during 2- to 5-min intervals both before and after IL-1 $\beta$ and $\mathrm{PGE}_{2}$ administration. All data were normalized to facilitate statistical comparisons.

One-way ANOVA was used to compare parameters with normal distribution and equal variance. Multiple comparisons were performed using Tukey-Kramer's HSD post hoc test. The
Wilcoxon test (two groups) and Kruskal-Wallis test ( $>$ two groups) were used for nonparametric measurements and data with non-Gaussian distributions or unequal variance. Change in variables over time was examined using MANOVA repeated measures design. Three-way ANOVA and logistic regression were used to evaluate differences between independent variables. The Spearman rank correlation test was used to determine correlations between variables. Data are presented as mean \pm SEM. A value of $p<0.05$ was considered statistically significant.

\section{RESULTS}

Respiration during normoxia. Animals given IL- $1 \beta$ exhibited a significantly lower $\mathrm{f}_{\mathrm{R}}$ than control animals $(p<0.01)$ and animals treated only with indomethacin $(p<0.05$; Table 1, Fig. 2). LPS also tended to reduce $f_{R}$ compared with the control $(p=0.079)$ and indomethacin only $(p=0.064)$. A lower $\mathrm{f}_{\mathrm{R}}$ during normoxia was correlated to a longer gasping duration $(p<0.0001)$, a depressed gasping frequency $(p<$ $0.0001)$, and reduced survival $(p<0.01)$. Indomethacin reversed the depressive effects of IL- $1 \beta$ and LPS on $f_{R}$ but did not stimulate respiration above basal levels in control animals. Respiratory frequency was higher in animals studied using barometric plethysmography than in those examined using flow plethysmography $(p<0.001)$. Treatment had no effect on inspiratory time, expiratory time, tidal volume, and minute ventilation (Fig. 2). Skin temperature during normoxia (34.6 \pm $0.1^{\circ} \mathrm{C}$ ) did not differ between groups.

Response to anoxia. All animals displayed a biphasic response to anoxia with the following characteristic stages: 1) hyperpnea, 2) primary apnea, 3) gasping, and 4) secondary or terminal apnea (Table 2, Fig. 1) (26). IL-1 $\beta$ significantly lowered the total gasping frequency compared with control $(p$ $<0.01$ ). Indomethacin did not prevent this depression of gasping. IL-1 $\beta$, LPS, and indomethacin had no effect on the duration of hyperpnea, primary apnea, or gasping and did not alter the duration or frequency of the three gasping phases. The duration of secondary apnea and time of autoresuscitation in survivors as well as the duration of anoxic exposure (685 \pm $12 \mathrm{~s})$ also did not differ between treatment groups.

Both IL- $1 \beta$ and LPS worsened recovery after anoxia. Survival was significantly lower in animals given IL-1 $\beta$ than in control animals and animals treated with indomethacin $(p<$ 0.05; Fig. 3). Similarly, animals given LPS died more readily than control animals $(p<0.05)$ and animals that received only indomethacin $(p<0.01)$. Pretreatment with indomethacin

Table 1. Respiratory effects of IL-1 $\beta$ and indomethacin using barometric plethysmography

\begin{tabular}{|c|c|c|c|c|}
\hline & \multicolumn{2}{|c|}{$\mathrm{NaCl}$ pretreatment } & \multicolumn{2}{|c|}{ Indomethacin pretreatment } \\
\hline & $\mathrm{NaCl}$ & IL- $1 \beta$ & $\mathrm{NaCl}$ & IL- $1 \beta$ \\
\hline Animals $(n)$ & 12 & 12 & 6 & 13 \\
\hline Hyperpnea (s) & $52 \pm 7$ & $65 \pm 4$ & $53 \pm 6$ & $54 \pm 3$ \\
\hline Primary apnea (s) & $22 \pm 4$ & $24 \pm 4$ & $22 \pm 8$ & $15 \pm 3$ \\
\hline Gasping (s) & $472 \pm 44$ & $640 \pm 59$ & $425 \pm 22$ & $525 \pm 25$ \\
\hline Autoresuscitation (s) & $1102 \pm 93$ & $1154 \pm 95$ & $878 \pm 96$ & $1094 \pm 46$ \\
\hline
\end{tabular}



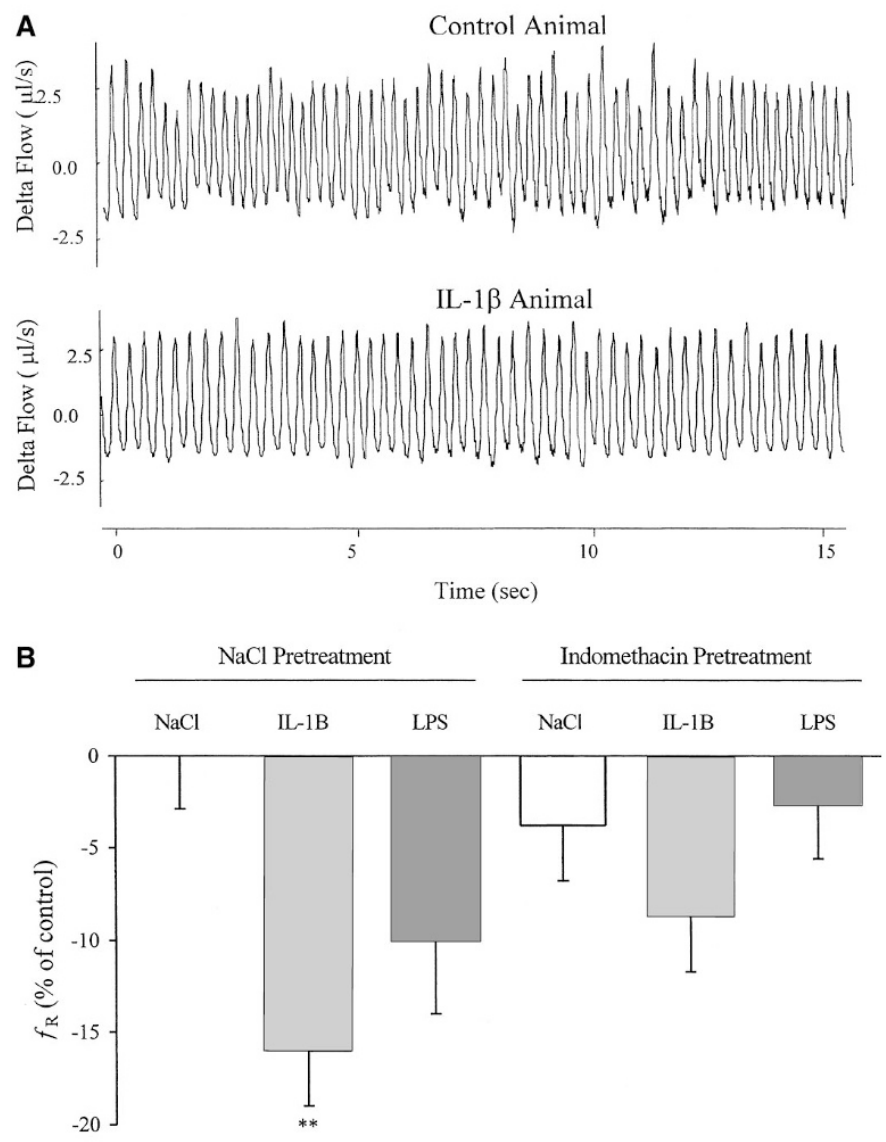

Figure 2. Effects of IL-1 $\beta$, LPS, and indomethacin on basal respiration. $A$, Flow plethysmograph recording depicts respiration during normoxia for a control animal and an IL- $1 \beta$-treated animal. IL- $1 \beta$ depressed $f_{R}$ but did not alter inspiratory time, expiratory time, tidal volume, or minute ventilation. $B$, $\mathrm{f}_{\mathrm{R}}$ during normoxia was compared between all animals according to group ( $n$ $=112$ ). $\mathrm{NaCl}$ or indomethacin was given before a second injection of $\mathrm{NaCl}$, IL- $1 \beta$, or LPS ( $\square, \mathrm{NaCl}$; 瞵, IL- $1 \beta$; $\square$, LPS). IL- $\beta$ reduced $\mathrm{f}_{\mathrm{R}}$ compared with control $(p<0.01)$ and indomethacin only $(p<0.05)$. Animals given LPS also tended to breathe more slowly than control animals $(p=0.079)$ and animals treated only with indomethacin $(p=0.064)$. Indomethacin attenuated the depressive effects of IL- $1 \beta$ and LPS but did not alter $f_{R}$ in control animals. Data are presented as mean \pm SEM. $* * p<0.01$ compared with control.

significantly improved the outcome of animals subsequently given IL-1 $\beta$ and LPS $(p<0.05)$.

Skin temperature decreased similarly during anoxia in all groups to $32.5 \pm 0.2^{\circ} \mathrm{C}$. No difference in chamber temperature $\left(29.7 \pm 0.1^{\circ} \mathrm{C}\right)$, animal weight $(15.5 \pm 0.2 \mathrm{~g})$, or sex distribution was observed between groups. Skin and chamber temperature as well as animal sex were not correlated with any respiratory variables or survival. The type of plethysmograph system also had no effect on anoxic response.

Brainstem respiratory activity. IL- $1 \beta$ applied to the brainstem-spinal cord preparation for $30 \mathrm{~min}$ did not alter burst distance (7.0 $\pm 1.7 \mathrm{~s})$ compared with control $(7.0 \pm 0.7 \mathrm{~s}$; Fig. 4). IL-1 $\beta$ perfusion for $60 \mathrm{~min}$ also had no significant effect on respiratory activity $\left(\mathrm{f}_{\mathrm{R}} ;-4.5 \pm 1.8 \%\right.$ of control). $\mathrm{PGE}_{2}$ application increased burst distance (20.8 $\pm 3.5 \mathrm{~s})$ compared with control $(9.3 \pm 1.3 \mathrm{~s})$, thereby decreasing $\mathrm{f}_{\mathrm{R}}(p<0.01)$. This effect was dose dependent and reversible within 20 min of reperfusion with control aCSF.

\section{DISCUSSION}

The principal finding of this study is that peripheral IL- $1 \beta$ depresses $f_{R}$ and worsens recovery from anoxic challenge in neonatal rats and that these effects are attenuated by pretreatment with indomethacin. In addition, this study reveals that IL- $1 \beta$ has no direct effect on respiratory rhythm generation in the isolated brainstem, whereas $\mathrm{PGE}_{2}$ significantly inhibits brainstem respiratory neurons. Thus, we propose that an activated immune system may alter central respiration and autoresuscitation via a cytokine-induced, prostaglandin-mediated pathway.

Two different plethysmograph systems were used to evaluate the effects of IL- $1 \beta$ on respiration and anoxic survival. Both recording methods revealed essentially similar treatment results. However, $f_{R}$ during normoxia was higher in animals examined using the barometric method, possibly because of an increased stress response resulting from a shorter acclimation period during normoxia and the lack of handling before experimentation. The more pronounced effects of IL- $1 \beta$ and indomethacin on basal respiration but not anoxic response in these potentially more stressed animals are consistent with previous work showing that stress elevates $f_{R}$ during normoxia but does not alter the respiratory response to hypoxia (27).

Animals given IL-1 $\beta$ exhibited a sustained respiratory depression throughout normoxia and anoxia, which may have contributed to their markedly reduced survival rate. These findings are in accordance with other studies demonstrating that IL- $1 \beta$ depresses respiration and adversely affects recovery from apnea induced by laryngeal stimulation $(6,7)$. However, the specific pathway by which IL- $1 \beta$ acts cannot be determined with our methods. Direct transport mechanisms have been demonstrated for IL-1 $\beta$ (28), although they have low capacity and are rapidly saturated. Furthermore, indomethacin does not affect this active transport and receptors for IL-1 are predominantly present on barrier-related cells (29). Because IL-1 $\beta$ applied directly to the brainstem preparation does not alter respiratory activity, it is unlikely that direct activation of brainstem areas by IL- $1 \beta$ trough this transport mechanism or via distant circumventricular organs plays a major role in the induction of the respiratory effects seen in the present study.

Instead, our study implicates a mediatory role of prostaglandins in these IL- $1 \beta$-induced respiratory effects. This is consistent with reports that prostaglandin mediates other IL- $1 \beta$ actions beyond the BBB [for review, see (11)] and can in itself depress both fetal and neonatal breathing (14-17). Furthermore, prostaglandin has been shown to inhibit the rhythmgenerating neurons of the pre-Bötzinger complex involved in both eupnea and gasping $(30,31)$, which may reduce the animal's ability to autoresuscitate. It was recently shown that circulating IL- $1 \beta$ binds to its receptor located on vascular endothelial cells at the BBB in the brainstem and induces COX-2 and microsomal PGE synthase mRNA expression within an hour of i.v. administration (32). This results in a local release of $\mathrm{PGE}_{2}$ and the subsequent activation of neurons in the VLM and NTS with highly expressed $\mathrm{PGE}_{2}$ receptors. This is corroborated by the findings of a similar c-fos and $\mathrm{PGE}_{2}$ receptor mRNA expression in the VLM and NTS, as that seen $1 \mathrm{~h}$ after i.v. IL- $1 \beta$ is detected $45 \mathrm{~min}$ after injection of $\mathrm{PGE}_{2}$ 
Table 2. Respiratory effects of IL-1, LPS, and indomethacin using flow plethysmography

\begin{tabular}{|c|c|c|c|c|c|c|}
\hline & \multicolumn{3}{|c|}{$\mathrm{NaCl}$ pretreatment } & \multicolumn{3}{|c|}{ Indomethacin pretreatment } \\
\hline Animals $(n)$ & 10 & 14 & 11 & 12 & 11 & 11 \\
\hline Hyperpnea (s) & $64 \pm 4$ & $63 \pm 4$ & $61 \pm 4$ & $60 \pm 3$ & $64 \pm 4$ & $62 \pm 4$ \\
\hline Primary apnea (s) & $13 \pm 2$ & $23 \pm 5$ & $16 \pm 5$ & $23 \pm 5$ & $18 \pm 1$ & $17 \pm 2$ \\
\hline Gasping (s) & $442 \pm 21$ & $481 \pm 28$ & $515 \pm 34$ & $518 \pm 26$ & $571 \pm 41$ & $472 \pm 38$ \\
\hline Autoresuscitation (s) & $1024 \pm 39$ & $1107 \pm 39$ & $1088 \pm 20$ & $1113 \pm 46$ & $1138 \pm 67$ & $1069 \pm 49$ \\
\hline
\end{tabular}

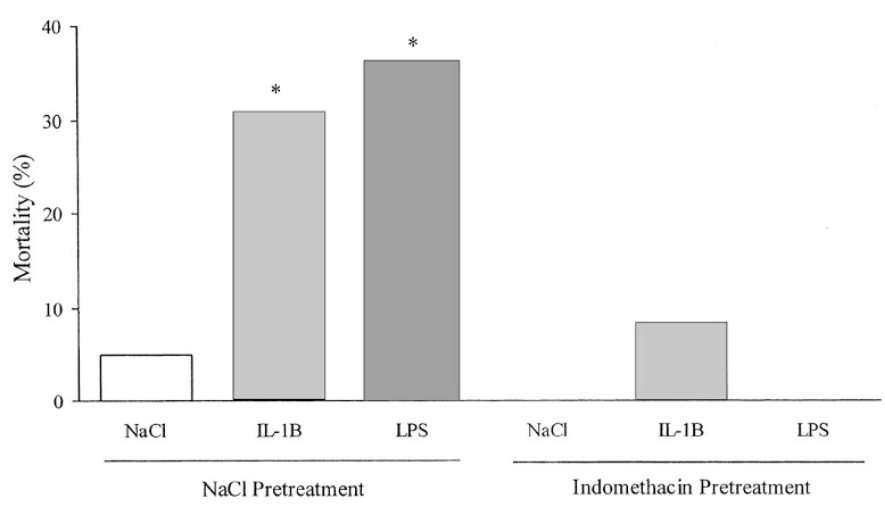

Figure 3. Effects of IL-1 $\beta$, LPS, and indomethacin on the ability to autoresuscitate after hypoxic apnea. Animals given IL-1 $\beta$ and LPS died more readily than control animals $(p<0.05)$ and animals treated only with indomethacin $(p$ $<0.05$ and $p<0.01$, respectively; $\square, \mathrm{NaCl}$; 膡, IL-1 $\beta$; $\mathbf{\square}$, LPS). Indomethacin improved outcome of these animals $(p<0.05)$. Data are presented as mean \pm SEM. ${ }^{*} p<0.05$ compared with control.

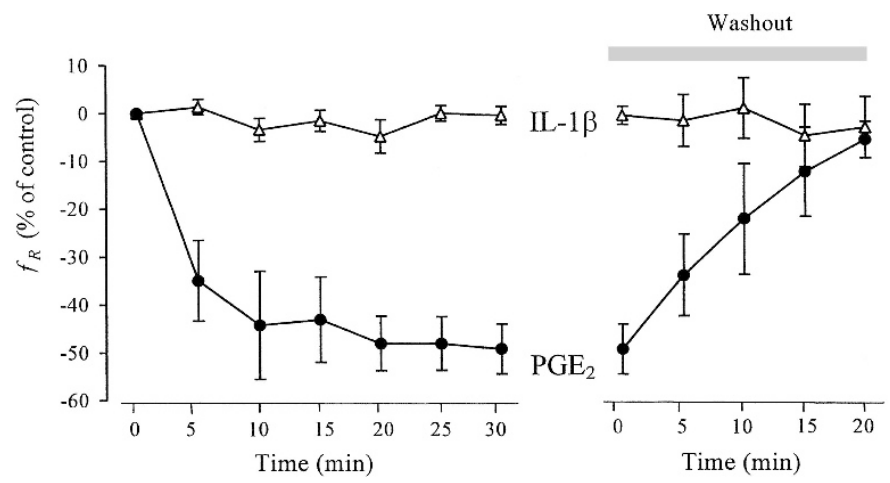

Figure 4. Effects of IL- $1 \beta$ and PGE $_{2}$ on respiratory rhythm generation. IL-1 $\beta$ $(\triangle)$ and $\mathrm{PGE}_{2}(\bullet)$ were applied to the brainstem-spinal cord preparation of neonatal rats. IL- $1 \beta$ did not change $f_{R}$, whereas $P E_{2}$ reversibly inhibited $f_{R}$ $(p<0.01)$. Data are presented as mean \pm SEM.

in the lateral ventricles (33). It is possible that the effects of peripheral IL- $1 \beta$ and LPS are mediated by COX-2 mRNA production, as indicated by several previous studies and subsequent release of $\mathrm{PGE}_{2}$, although this was not investigated here. The proposed cascade of events involving prostaglandin synthesis and action may explain why direct application of IL- $1 \beta$ to respiratory neurons in the brainstem-spinal cord preparation - where the BBB endothelium is absent and thus IL-1 $\beta$ could not induce prostaglandin release- had no effect on respiratory neuronal activity.

The prostaglandin-dependent action on central respiratory neurons may be mediated by both central and vagal pathways, and the predominant signaling pathway could be affected by factors such as drug administration route and dose $(34,35)$. It is possible that peripheral IL- $1 \beta$ communicates with the NTS by acting at vagal afferents in a prostaglandin-dependent manner (36), subsequently affecting respiratory centers. It is worth noting that vagotomy does not prevent IL- $1 \beta$ 's induction of fos-ir expression in the NTS and RVLM $(36,37)$. It also does not affect indomethacin's reduction of expression in these respiratory regions or indomethacin's stimulation of respiration $(20,36,37)$. This supports the proposal of a central rather than vagal prostaglandin-dependent pathway for IL- $1 \beta$ action upon brainstem respiratory-related neurons in the newborn rat.

LPS induced similar effects on respiration, although less pronounced, as those seen with IL- $1 \beta$. Previous studies have demonstrated that LPS stimulates macrophages to release IL$1 \beta$, resulting in detectable levels of IL- $1 \beta$ in the plasma at $2 \mathrm{~h}$ and the brain at $6 \mathrm{~h}$ after intraperitoneal injection (38). LPS (i.p.) also activates prostaglandin-synthesizing enzymes; however, it does so following a more delayed time course than with direct application of IL-1 $\beta$ (i.v.) $(39,40)$. Although a longer duration between the inflammatory challenge and respiratory recordings in our study may have produced greater alterations in respiration and the ability to autoresuscitate, a shorter time period was chosen to limit confounding systemic changes. The effects of IL-1 $\beta$ and LPS on respiration and survival in the present study do not seem to result from other drug-induced centrally mediated responses such as fever or sleep. Temperature measurements during normoxia correspond to previously reported values for rats of similar age (41), and no difference was observed between treatment groups. Furthermore, all animals exhibited a similar characteristic hypothermic response to reduced $\mathrm{O}_{2}$ concentrations (42). These findings are in agreement with studies showing that IL- $1 \beta$ and LPS do not elicit a significant temperature increase in rats until at least $90 \mathrm{~min}$ after intraperitoneal administration (43, 44). In addition, our recordings were performed in the light cycle within 90 min of drug injection, thus making the sleep-inducing effects of IL- $1 \beta$ and LPS shown previously to begin at $2 \mathrm{~h}$ after drug administration during the light cycle unlikely (45), and no difference in gross motor activity was observed between treatment groups.

Although prostaglandin may relay IL- $1 \beta$ and LPS signals to the central respiratory network during an immune challenge, it does not seem to influence eupnea in healthy 7-d-old rats. The inability of indomethacin to stimulate breathing beyond basal levels in such animals may be explained by the critical transition in the respiratory effects of $\mathrm{PGE}_{2}$ during early postnatal 
development. Although $\mathrm{PGE}_{2}$ inhibits breathing movements in the fetus and directly after birth $(14,15)$, it later induces little or no change in central respiration during normal conditions (17). Consequently, the effects of indomethacin on eupneic breathing will vary depending on the animal's immune state and the specific stage of perinatal development at which it is given.

Prostaglandin seems to play a critical role in the ability of rats to autoresuscitate and survive an anoxic challenge, yet no alterations in the anoxic respiratory pattern by indomethacin were detected. Prostaglandin involvement during anoxia remains likely as indomethacin effects were seen both before and after $\mathrm{N}_{2}$ exposure. In addition, prostaglandin is considered to be one of the inhibitory neuromodulators contributing to respiratory depression during anoxia (46). In addition to its effects on neuronal activity, prostaglandin may diminish the responsiveness to anoxia by reducing central chemosensitivity to $\mathrm{CO}_{2}$ $(12,17,30,31)$. Prostaglandin may do so by acting on $\mathrm{PGE}_{2}$ receptors highly expressed in the NTS, nucleus ambiguus, and parabrachial nucleus or by hyperpolarizing pre-Bötzinger neurons recently shown to possess intrinsic hypoxic chemosensitivity and respond to changes in $\mathrm{PCO}_{2}$. In exerting these effects, prostaglandin may contribute to the decreased ability to autoresuscitate and thereby worsen recovery from anoxic stress.

The present investigation explored one possible mediator of recurrent apnea and infection: IL- $1 \beta$ and a mechanism by which it may exert modulating effects on vital autonomic function within the CNS. This study shows that an inflammatory response can inhibit respiration as well as the ability to autoresuscitate and survive anoxic challenge. We propose that these effects are mediated by IL- $1 \beta$ and its induction of prostaglandin release in the vicinity of respiratory neurons in the brainstem. Our findings support the hypothesis that infection may induce apnea and possibly also sudden infant death syndrome via a prostaglandindependent, cytokine-mediated pathway.

\section{REFERENCES}

1. Raza M, Blackwell CC 1999 Sudden infant death syndrome, virus infections and cytokines. FEMS Immunol Med Microbiol 25:85-96

2. Guntheroth W 1989 Interleukin-1 as intermediary causing prolonged sleep apnea and SIDS during respiratory infections. Med Hypotheses 28:121-123

3. Dinarello C 1991 Interleukin-1 and interleukin-1 antagonism. Blood 77:1627-1652

4. Lindgren C, Grogaard J 1996 Reflex apnoea response and inflammatory mediators in infants with respiratory tract infection. Acta Paediatr 85:798-803

5. Vege Å, Rognum TO, Aasen AO, Saugstad OD 1998 Are elevated cerebrospinal fluid levels of IL-6 in sudden unexplained deaths, infectious deaths and deaths due to heart/lung disease in infants and children due to hypoxia? Acta Paediatr 87:819-824

6. Stoltenberg L, Sunder T, Almaas R, Storm H, Rognum TO, Saugstad OD 1994 Changes in apnea and autoresuscitation in piglets after intravenous and intrathecal interleukin-1B injection. J Perinat Med 22:421-432

7. Froen JF, Akre H, Stray-Pedersen B, Saugstad OD 2000 Adverse effects of nicotine and interleukin-1beta on autoresuscitation after apnea in piglets: implications for sudden infant death syndrome. Pediatrics 105(4). Available at: www.pediatrics.org/ cgi/content/full/105/4/e52

8. Koshiya N, Smith JC 1999 Neuronal pacemaker for breathing visualized in vitro. Nature 400:360-363

9. Ericsson A, Kovacs KJ, Sawchenko PE 1994 A functional anatomical analysis of central pathways subserving the effects of interleukin-1 on stress-related neuroendocrine neurons. J Neurosci 14:897-913

10. de Boer A, Breimer DD 1998 Cytokines and blood-brain barrier permeability. Prog Brain Res 115:425-451

11. Engblom D, Ek M, Saha S, Ericsson-Dahlstrand A, Jakobsson PJ, Blomqvist A 2002 Prostaglandins as inflammatory messengers across the blood-brain barrier. J Mol Med $80: 5-15$

12. Tai T, MacLusky NJ, Adamson SL 1994 Ontogenesis of prostaglandin E2 binding sites in the brainstem of the sheep. Brain Res 652:28-39

13. Ek M, Arias C, Sawchenko P, Ericsson-Dahlstrand A 2000 Distribution of the EP3 prostaglandin $\mathrm{E}(2)$ receptor subtype in the rat brain: relationship to sites of interleukin-1-induced cellular responsiveness. J Comp Neurol 428:5-20
14. Kitterman J, Liggins GC, Fewell JE, Tooley WH 1983 Inhibition of breathing movements in fetal sheep by prostaglandins. J Appl Physiol 54:687-692

15. Guerra FA, Savich RD, Wallen LD, Lee CH, Clyman RI, Mauray FE, Kitterman JA 1988 Prostaglandin E2 causes hypoventilation and apnea in newborn lambs. J Appl Physiol 64:2160-2166

16. Long W 1988 Prostaglandins and control of breathing in newborn piglets. J App Physiol 64:409-418

17. Tai TC, Adamson SL 2000 Developmental changes in respiratory, febrile, and cardiovascular responses to PGE(2) in newborn lambs. Am J Physiol 278:1460-1473

18. Hoch B, Bernhard M 2000 Central apnoea and endogenous prostaglandins in neonates. Acta Paediatr 89:1364-1368

19. Wolsink JG, Berkenbosch A, DeGoede J, Olievier CN 1994 The influence of indomethacin on the ventilatory response to $\mathrm{CO}_{2}$ in newborn anaesthetized piglets. J Physiol 477:339-345

20. Jansen A, De Boeck C, Ioffe S, Chernick V 1984 Indomethacin-induced fetal breathing: mechanism and site of action. J Appl Physiol 57:360-365

21. Mortola JP 2001 Respiratory Physiology of Newborn Mammals: A Comparative Perspective. The Johns Hopkins University Press, Baltimore, pp 171-185

22. Yuan S, Runold M, Lagercrantz H 1997 Adrenalectomy reduces the ability of newborn rats to gasp and survive anoxia. Acta Physiol Scand 159:285-292

23. Herlenius E, Lagercrantz H, Yamamoto Y 1997 Adenosine modulates inspiratory neurons and the respiratory pattern in the brainstem of neonatal rats. Pediatr Res $42: 46-53$

24. Suzue T 1984 Respiratory rhythm generation in the in vitro brain stem-spinal cord preparation of the neonatal rat. J Physiol 354:173-183

25. Gozal D, Torres JE, Gozal YM, Nuckton TJ 1996 Characterization and developmental aspects of anoxia-induced gasping in the rat. Biol Neonate 70:280-288

26. Campbell A, Cross KW, Dawes GS, Hyman AI 1966 A comparison of air and $\mathrm{O}_{2}$ in the hyperbaric chamber or by positive pressure ventilation in the resuscitation of newborn rabbits. J Pediatr 68:153-163

27. Dauger S, Nsegbe E, Vardon G, Gaultier C, Gallego J 1998 The effects of restraint on ventilatory responses to hypercapnia and hypoxia in adult mice. Respir Physio 112:215-225

28. Banks WA, Kastin AJ, Broadwell RD 1995 Passage of cytokines across the bloodbrain barrier. Neuorimmunomodulation 2:241-248

29. Ericsson A, Liu C, Hart RP, Sawchenko PE 1995 Type 1 interleukin-1 receptor in the rat brain: distribution, regulation, and relationship to sites of IL-1-induced cellular activation. J Comp Neurol 361:681-698

30. Ballanyi K, Lalley PM, Hoch B, Richter DW 1997 cAMP-dependent reversal of opioid- and prostaglandin-mediated depression of the isolated respiratory network in newborn rats. J Physiol 504:127-134

31. Solomon IC 2002 Modulation of gasp frequency by activation of pre-Bötzinger complex in vivo. J Neurophysiol 87:1664-1668

32. Ek M, Engblom D, Saha S, Blomqvist A, Jakobsson PJ, Ericsson-Dahlstrand A 2001 Inflammatory response: pathway across the blood-brain barrier. Nature 410:430-431

33. Zhang J, Rivest S 2000 A functional analysis of EP4 receptor-expressing neurons in mediating the action of prostaglandin E2 within specific nuclei of the brain in response to circulating interleukin-1beta. J Neurochem 74:2134-2145

34. Konsman JP, Tridon V, Dantzer R 2000 Diffusion and action of intracerebroventricularly injected interleukin-1 in the CNS. Neuroscience 101:957-967

35. Hansen MK, O'Connor KA, Goehler LE, Watkins LR, Maier SF 2001 The contribution of the vagus nerve in interleukin-1b-induced fever is dependent on dose. Am J Physiol 280:R929-R934

36. Ek M, Kurosawa M, Lundeberg T, Ericsson A 1998 Activation of vagal afferents after intravenous injection of interleukin-1beta: role of endogenous prostaglandins. J Neurosci 18:9471-9479

37. Ericsson A, Arias C, Sawchenko PE 1997 Evidence for an intramedullary prostaglandin-dependent mechanism in the activation of stress-related neuroendocrine circuitry by intravenous interleukin-1. J Neurosci 17:7166-7179

38. Quan N, Sundar SK, Weiss JM 1994 Induction of interleukin-1 in various brain regions after peripheral and central injections of lipopolysaccharide. J Neuroimmunol 49:125-134

39. Cao C, Matsumura K, Yamagata K, Watanabe Y 1995 Induction by lipopolysaccharide of cyclooxygenase-2 mRNA in rat brain: its possible role in the febrile response. Brain Res 697:187-196

40. Yamagata K, Matsumura K, Inoue W, Shiraki T, Suzuki K, Yasuda S, Sugiura H, Cao C, Watanabe Y, Kobayashi S 2001 Coexpression of microsomal-type prostaglandin E synthase with cyclooxygenase- 2 in brain endothelial cells of rats during endotoxininduced fever. J Neurosci 21:2669-2677

41. Seifert EL, Mortola JP 2000 Light-dark differences in the effects of ambient temperature on gaseous metabolism in newborn rats. J Appl Physiol 88:1853-1858

42. Gautier H, Murariu C, Bonora M 1997 Ventilatory and metabolic responses to ambient hypoxia or hypercapnia in rats exposed to CO hypoxia. J Appl Physiol $83: 253-261$

43. Cao C, Matsumura K, Yamagata K, Watanabe Y 1996 Endothelial cells of the rat brain vasculature express cyclooxygenase- 2 mRNA in response to systemic interleukin-1 beta: a possible site of prostaglandin synthesis responsible for fever. Brain Res 733:263-272

44. Rothwell NJ 1997 Sixteenth Gaddum Memorial Lecture December 1996. Neuroimmune interactions: the role of cytokines. Br J Pharmacol 121:841-847

45. Opp MR, Toth LA 1998 Somnogenic and pyrogenic effects of interleukin-1beta and lipopolysaccharide in intact and vagotomized rats. Life Sci 62:923-936

46. Ballanyi K, Onimaru H, Homma I 1999 Respiratory network function in the isolated brainstem-spinal cord of newborn rats. Prog Neurobiol 59:583-634 